MATHEMATICA, 60 (83), $\mathrm{N}^{\circ}$ 1, 2018, pp. 12-20

\title{
SOME WEIGHTED INEQUALITIES OF CHEBYSHEV TYPE VIA RL-APPROACH
}

\author{
MOHAMED BEZZIOU, ZOUBIR DAHMANI, and AMINA KHAMELI
}

\begin{abstract}
By using the Riemann-Liouville fractional integral operator, we establish new weighted results of Chebyshev inequality type. Other integral inequalities of fractional order are also proved. Some classical results can be deduced as special cases.
\end{abstract}

MSC 2010. 26D10, 26A33.

Key words. Riemann-Liouville integral operator, weighted Chebyshev functional.

\section{REFERENCES}

[1] K.M. Awan, J. Pecaric and A. Rehman, Steffensen's generalization of Chebyshev inequality, J. Math. Inequal., 9 (2015), 155-163.

[2] S. Belarbi and Z. Dahmani, On some new fractional integral inequalities, Journal of Inequalities in Pure and Applied Mathematics, 10, Article 86 (2009), 1-5.

[3] P. Cerone and S.S. Dragomir, Some new Ostrowski-type bounds for the Chebyshev functional and applications, J. Math. Inequal., 8 (2014), 159-170.

[4] P.L. Chebyshev, Sur les expressions approximatives des integrales definis par les autres prises entre les memes limite, Proc. Math. Soc. Charkov, 2 (1882), 93-98.

[5] Z. Dahmani, New inequalities in fractional integrals, International Journal of Nonlinear Sciences, 9 (2010), 493-497.

[6] Z. Dahmani, About some integral inequalities using Riemann-Liouville integrals, General Mathematics, 20 (2012), 63-69.

[7] Z. Dahmani, O. Mechouar and S. Brahami, Certain inequalities related to the Chebyshev's functional involving Riemann-Liouville operator, Bull. Math. Anal. Appl., 3 (2011), 38-44.

[8] Z. Dahmani and L. Tabharit, On weighted Gruss type inequalities via fractional integrals, Journal of Advanced Research in Pure Mathematics, 2 (2010), 31-38.

[9] S.S. Dragomir, A generalization of Gruss inequality in inner product spaces and applications, J. Math. Annal. Appl, 237 (1999), 74-82.

[10] F. Gorenflo and F. Mainardi, Fractional calculus: integral and differential equations of fractional order, Springer Verlag, Wien, 1997, pp. 223-276.

[11] A.McD. Mercer, An improvement of Grüss inequality, Journal of Inequalities in Pure and Applied Mathematics, 6, Article 93 (2005), 1-4.

[12] A.McD. Mercer and P. Mercer, New proofs of the Grüss inequality, Aust. J. Math. Anal. Appl., 1, Article 12 (2004), 1-6.

[13] A.M. Ostrowski, On an integral inequality, Aequationes Math., 4 (1970), 358-373.

[14] M.Z. Sarikatya and H. Yaldiz, New generalization fractional inequalities of OstrowskiGruss type, Lobachevskii J. Math., 34 (2013), 326-331.

DOI: $10.24193 /$ mathcluj.2018.1.02 
[15] M.Z. Sarikatya and N. Aktan, On weighted Chebyshev-Gruss like inequalities on time scales, J. Math. Inequal., 2 (2008), 185-195.

[16] M.Z. Sarikatya, On the Ostrowski type integral inequality, Acta Math. Univ. Comenian. (N.S.), LXXIX (2010), 129-134.

[17] M.Z. Sarikatya and A. Karaca, On the k-Riemann-Liouville fractional integral and applications, International Journal of Statistics and Mathematics, 1 (2014), 33-43.

Received June 19, 2017

Accepted November 4, 2017
University of Khemis Miliana, Algeria Department of Mathematics

UMAB, University of Mostaganem, Algeria Laboratory LPAM

Faculty of Exact Sciences and Informatics

E-mail: m.bezziou@univ-dbkm.dz

UMAB, University of Mostaganem, Algeria Laboratory LPAM

Faculty of Exact Sciences and Informatics E-mail: zzdahmani@yahoo.fr

E-mail: khameli.amina@gmail.com 